\title{
Placental Abruption Revealed by Hemoperitoneum: A Case Report
}

\author{
$\begin{array}{llll}\text { C. Bertholdt, } M D^{1} & \text { A. Vincent-Rohfritsch, } M D^{1} & \text { V. Tsatsaris, MD } & \text { F. Goffinet, MD }\end{array}$ \\ ${ }^{1}$ Maternité Port-Royal, Université Paris Descartes, Groupe Hospitalier \\ Cochin Broca, Hôtel-Dieu, Paris, France \\ Am J Perinatol Rep 2016;6:e424-e426.

\begin{abstract}
Address for correspondence C. Bertholdt, MD, Maternité Port-Royal, Université Paris Descartes, Groupe Hospitalier Cochin Broca, HôtelDieu, Assistance Publique-Hôpitaux de Paris, 53 avenue de l'Observatoire, 75014 Paris, France (e-mail: charline.bertholdt@gmail.com).
\end{abstract}
Abstract
Keywords
- placental abruption
- hemoperitoneum
- fetal heart rate
- abnormalities
- Couvelaire

Background Hemoperitoneum is a life-threatening surgical emergency. Diagnosis of the cause is often difficult, in particular, during pregnancy when it may be either obstetric or nonobstetric.

Case We report the case of a hemoperitoneum caused by the backflow of blood through a uterine tube, due to placental abruption.

Conclusion Hemoperitoneum in pregnant women with no other signs can reveal placental abruption. The difficulty in identifying the cause may delay appropriate management.
A spontaneous hemoperitoneum during the second or third trimester is a rare event that must be managed rapidly because of the potential risks to mother and fetus. At the same time, both its certain diagnosis and the identification of its cause are difficult. Hemoperitoneum in pregnant women appears in its most standard form as acute abdominal pain, sometimes accompanied by maternal shock, depending on its volume. Diagnosis during pregnancy is difficult because of its low prevalence and its nonspecific clinical findings; it is rarely mentioned initially as a differential diagnosis for acute abdominal pain. Diagnosis of the cause is also difficult because both obstetric and standard causes (vascular, hepatic, splenic, gynecologic, or hematologic) must be considered and because computed tomographic and magnetic resonance imaging are used less often during pregnancy. The speed of diagnosis and treatment is a key element in maternal and fetal outcomes.

\section{Case Report}

We report here the case of a 29-year-old woman, with no notable medical or surgical history, gravida 2, para 1 , who had a normal pregnancy with a vaginal delivery at term in 2012. The pregnancy in 2014 was proceeding normally until 30 weeks of gestation, when she sought care for uterine contractions and moderate vaginal bleeding at a level $2 \mathrm{~A}$ maternity unit, where the staff, suspecting preterm labor, rapidly began intravenous atosiban for tocolysis and transferred her to our level-3 facility. When she arrived at $11 \mathrm{Am}$, her blood pressure was $95 / 46 \mathrm{~mm} \mathrm{Hg}$, heart rate $100 \mathrm{bpm}$, and temperature $37.4^{\circ} \mathrm{C}$. The urinary dipstick test did not reveal proteinuria. Uterine contractions stopped, and a digital cervical examination showed a posterior medium long cervix, soft, and open $1 \mathrm{~cm}$. No evidence of vaginal bleeding was seen during the speculum examination. On obstetric ultrasound, we observed a fetus normal for gestation age, with an estimated weight of 1,660 g, an anterior placenta inserted low and apparently normal on imaging, and a cervical length of $22 \mathrm{~mm}$. The fetal heart rate was normal, hemoglobin $10.8 \mathrm{~g} / \mathrm{dL}$, and testing for infection negative. Specifically, her leukocyte count was $<10 \times 10^{9} / \mathrm{L}$, C-reactive protein $<5 \mathrm{mg} / \mathrm{L}$, and the vaginal swab and cytobacteriologic examination of the urine were both negative. Threatened preterm delivery was diagnosed. Tocolysis by atosiban continued, and corticosteroid (betamethasone) therapy for fetal lung maturation began.

At $10 \mathrm{PM}$, the woman reported intense, diffuse abdominal pain. The uterus was soft, and the findings of the digital cervical examination were unchanged. The fetal heart rate was normal. Ultrasound showed good fetal activity but revealed an intrauterine hematoma measuring $59 \times 66$ $\times 109 \mathrm{~mm}$, in a left lateral position relative to the placenta, associated with moderately abundant left intra-abdominal received

July 25, 2016

accepted after revision

October 17, 2016
DOI http://dx.doi.org/

$10.1055 / \mathrm{s}-0036-1597267$. ISSN 2157-6998.
Copyright $\odot 2016$ by Thieme Medical

Publishers, Inc., 333 Seventh Avenue, New York, NY 10001, USA. Tel: +1(212) 584-4662.
License terms

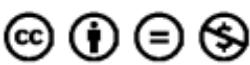


effusion. Hemoglobin was $8.3 \mathrm{~g} / \mathrm{dL}$, for a loss of $2.5 \mathrm{~g} / \mathrm{dL}$ since admission. Monitoring of blood pressure, heart rate, and oxygen saturation continued in the delivery room, and fetal cardiotocography was continuously recorded. We controlled the pain with oral paracetamol and nefopam. At midnight, the mother remained hemodynamically stable; her abdomen and uterus were soft and painless. Ultrasound showed increased peritoneal effusion, now on both sides of the abdomen. Fetal activity and heart rate remained normal, and hemoglobin was stable at $8 \mathrm{~g} / \mathrm{dL}$. The patient remained under continuous monitoring in the delivery room.

At 08 Am the next morning, her blood pressure was stable at $130 / 80 \mathrm{~mm} \mathrm{Hg}$ and her heart rate $120 \mathrm{bpm}$; fetal heart rate was normal, and hemoglobin remained stable at $8 \mathrm{~g} / \mathrm{dL}$. On ultrasound, fetal activity was good and the intrauterine hematoma stable, but the peritoneal effusion had increased further and was now estimated at more than a liter. Hypothesizing a uterine rupture, despite the absence of any uterine scar or any history of an intrauterine procedure, we decided to perform a cesarean delivery under general anesthesia. We used an infraumbilical midline laparotomy to allow exploration of the peritoneal cavity if the hemoperitoneum turned out to have a nonobstetric cause. A moderate hemoperitoneum was found. The uterus appeared purplish all over, with the typical appearance of a Couvelaire uterus ( - Fig. 1); it thus suggested placental abruption. No uterine rupture was observed. The hemoperitoneum was caused by backflow of intrauterine blood through the left intrauterine tube. We

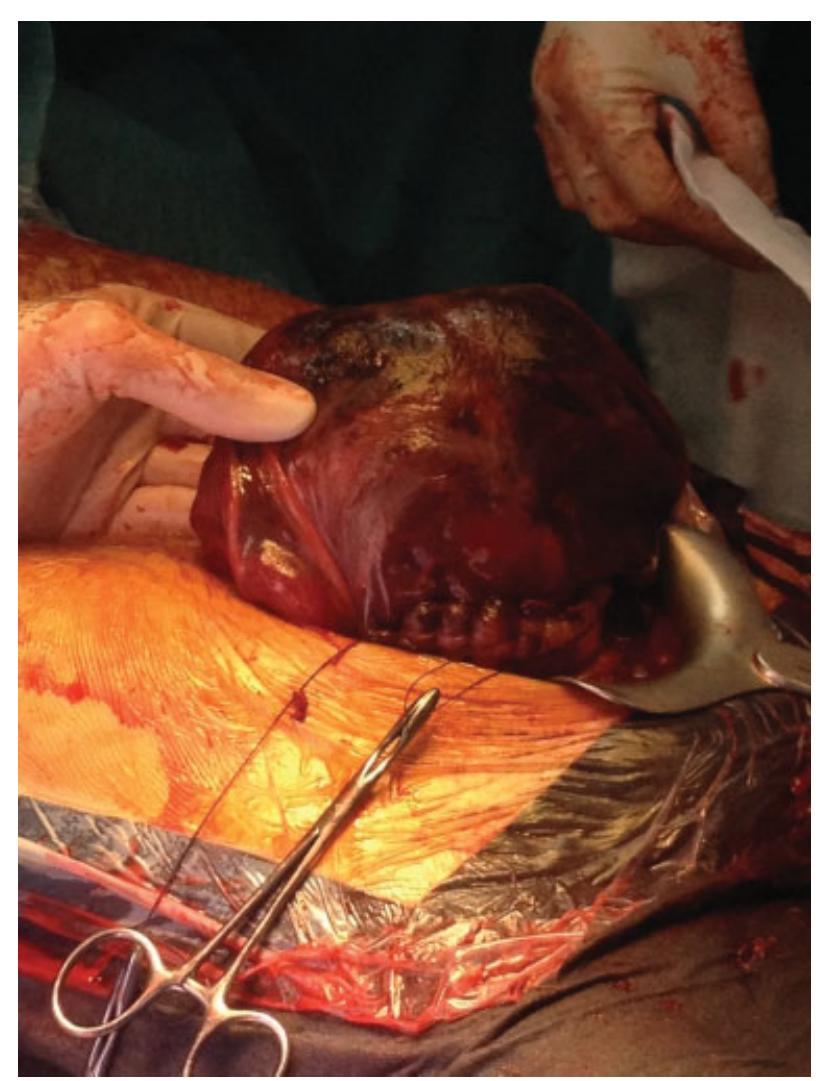

Fig. 1 Couvelaire uterus: extravasation of blood into the uterine musculature during placental abruption. performed a segmental transverse incision of the uterus, which proved to be transplacental. This cesarean delivered a girl weighing 1,655 $\mathrm{g}$ (appropriate for gestational age), Apgar 3/6/9, pH 7.34; she was immediately transferred to the neonatal intensive care unit. The placenta was anterior and inserted low. The delivery of the placenta was accompanied by numerous clots. Laboratory tests for coagulation were normal during the stay and until delivery, except for fibrinogen, which fell to $1.6 \mathrm{~g} / \mathrm{L}$ few hours before cesarean section. The mother received a transfusion of two units of packed red blood cells, $3 \mathrm{~g}$ of fibrinogen to keep its concentration $>2 \mathrm{~g} / \mathrm{L}$, and $2 \mathrm{~g}$ of tranexamic acid. The postoperative course was simple, and no signs of preeclampsia developed. Her hemoglobin rose to $10 \mathrm{~g} / \mathrm{dL}$ and remained stable through her discharge on day 5 . The infant's course was also favorable, and she was discharged after 41 days.

The pathology examination of the placenta showed a retroplacental cup-shaped depression measuring $8 \mathrm{~cm}$ on its largest axis, which confirmed the diagnosis of placental abruption, associated with thrombosis of $20 \%$ of the chorionic plate vessels. Maternal immunological and thrombophilia testing was performed for etiologic purposes; results were normal.

\section{Discussion}

Placental abruption is a well-known obstetric accident and a life-threatening emergency. A report that the standard clinical triad combining vaginal bleeding, abdominal and pelvic pain, and uterine hypertonia is found in only approximately $10 \%$ of cases ${ }^{1}$ explains the diagnostic difficulties.

To our knowledge, hemoperitoneum has never been reported to be associated with placental abruption. The nonobstetric causes of hemoperitoneum during pregnancy include ruptures of the maternal umbilical vein, aneurysms of the splenic artery or vein, spontaneous rupture of the liver or spleen, and hematologic causes (coagulopathy). ${ }^{2-5}$

The causes of spontaneous hemoperitoneum during the second and third trimesters of pregnancy nonetheless seem to be predominantly obstetric. The most frequent of these obstetric causes is rupture of dilated uterine vessels (varices). ${ }^{6,7}$ The literature also includes cases involving rupture of a uterine artery aneurysm ${ }^{8}$ or an unscarred uterus, ${ }^{9}$ especially in women with endometriosis ${ }^{10}$ or placentation abnormalities (such as placenta percreta). ${ }^{11,12}$

In this case report, the context and clinical picture at admission did not suggest placental abruption. Only the ultrasound examination revealed the presence of an intrauterine hematoma, and nothing about its appearance suggested placental abruption. These features did not initially seem to the obstetric team adequate to justify emergency delivery of this very preterm fetus. The appearance of hemoperitoneum made the diagnosis still more difficult, for this clinical feature has never, to the best of our knowledge, been described in the literature in association with placental abruption. In view of the left anterolateral position of the placenta, very near the uterine tube, we supposed that the hemoperitoneum came from the progressive evacuation of 
blood from the hematoma in the abdominal cavity. This backflow may have prevented the complete detachment of the placenta and thus enabled the favorable outcome. If we had known that placental abruption could be associated with hemoperitoneum, we might have performed the cesarean delivery earlier. We estimate the delay in delivery at 12 to 24 hours.

The onset of hemoperitoneum during the second and third trimesters can reveal a voluminous placental abruption. This diagnosis must be considered among the obstetric causes of hemoperitoneum, especially when imaging also shows an intrauterine hematoma, to avoid a delay in diagnosis that could have major consequences on both fetal and maternal morbidity and mortality.

\section{References}

1 Boisramé T, Sananès N, Fritz G, et al. [Abruptio placentae. Diagnosis, management and maternal-fetal prognosis: a retrospective study of 100 cases]. Gynecol Obstet Fertil 2014;42(2):78-83

2 Groussolles M Jr, Merveille M, Alacoque X, Vayssiere C, Reme JM, Parant 0 . Rupture of a splenic artery aneurysm in the first trimester of pregnancy. J Emerg Med 2011;41(1):e13-e16

3 Cimbanassi S, Aseni P, Mariani A, Sammartano F, Bonacina E, Chiara O. Spontaneous hepatic rupture during pregnancy in a patient with peliosis hepatis. Ann Hepatol 2015;14(4):553-558
4 Elghanmi A, Mohamed J, Khabouz S. Spontaneous splenic rupture in pregnancy. Pan Afr Med J 2015;21:312

5 Pommier C, Perrin C, Dorne R, De Roissard JP, Arnould P. [Hemoperitoneum and pregnancy in a patient with von Willebrand's disease type 3]. Ann Fr Anesth Reanim 2002;21(5):436-439

6 Lim PS, Ng SP, Shafiee MN, Kampan N, Jamil MA. Spontaneous rupture of uterine varicose veins: a rare cause for obstetric shock. J Obstet Gynaecol Res 2014;40(6):1791-1794

7 Nguessan KLP, Mian DB, Aissi GA, Oussou C, Boni S. Spontaneous rupture of uterine varices in third trimester pregnancy: an unexpected cause of hemoperitoneum. A case report and literature review. Clin Exp Obstet Gynecol 2013;40(1):175-177

8 Gavanier D, Orsoni M, Dupuis O, Valette PJ. [Spontaneous hemoperitoneum during pregnancy and uterine artery aneurysm]. Gynecol Obstet Fertil 2012;40(11):711-714

9 Abdalla N, Reinholz-Jaskolska M, Bachanek M, Cendrowski K, Stanczak R, Sawicki W. Hemoperitoneum in a patient with spontaneous rupture of the posterior wall of an unscarred uterus in the second trimester of pregnancy. BMC Res Notes 2015;8:603

10 Cozzolino M, Corioni S, Maggio L, Sorbi F, Guaschino S, Fambrini M. Endometriosis-related hemoperitoneum in pregnancy: a diagnosis to keep in mind. Ochsner J 2015;15(3):262-264

11 Vyjayanthi S, Rajesh U, Bloomfield TH. Haemoperitoneum due to placenta percreta in the third trimester mimicking placental abruption. J Obstet Gynaecol 2002;22(6):690-691

12 Blé RK, Adjoussou S, Doukoure B, et al. [Placenta percreta: a rare etiology of spontaneous uterine perforation in the second trimester of pregnancy]. Gynecol Obstet Fertil 2011;39(1): e11-e14 